Article

\title{
Impact of the Selected Disturbing Factors on Accuracy of the Distance Measurement with the Use of Ultrasonic Transducers in a Hard Coal Mine
}

\author{
Sławomir Bartoszek ${ }^{1, *(1)}$, Grzegorz Ćwikła ${ }^{2}\left(\mathbb{D}\right.$, Gabriel Kost $^{2}\left(\mathbb{D}\right.$ and Krzysztof Nieśpiałowski ${ }^{1}{ }^{1(0)}$ \\ 1 Division of Mechatronic Systems, KOMAG Institute of Mining Technology, Pszczyńska 37, \\ 44-100 Gliwice, Poland; kniespialowski@komag.eu \\ 2 Faculty of Mechanical Engineering, Silesian University of Technology, Konarskiego 18A, \\ 44-100 Gliwice, Poland; grzegorz.cwikla@polsl.pl (G.Ć.); gabriel.kost@polsl.pl (G.K.) \\ * Correspondence: sbartoszek@komag.eu
}

check for updates

Citation: Bartoszek, S.; Ćwikła, G.; Kost, G.; Nieśpiałowski, K. Impact of the Selected Disturbing Factors on Accuracy of the Distance

Measurement with the Use of

Ultrasonic Transducers in a Hard

Coal Mine. Energies 2022, 15, 133.

https://doi.org/10.3390/en15010133

Academic Editors: Rajender Gupta and Nikolaos Koukouzas

Received: 8 November 2021

Accepted: 22 December 2021

Published: 24 December 2021

Publisher's Note: MDPI stays neutral with regard to jurisdictional claims in published maps and institutional affiliations.

Copyright: (C) 2021 by the authors. Licensee MDPI, Basel, Switzerland. This article is an open access article distributed under the terms and conditions of the Creative Commons Attribution (CC BY) license (https:/ / creativecommons.org/licenses/by/ $4.0 /)$.

\begin{abstract}
The article presents tests on the possibility of using ultrasonic transducers for accurate distance measurement in hard coal mines. In order to check the impact of selected disturbing factors on the measurement results, test stands were built, and then a full cycle of measurements with the use of different transducers (AR30 and AR41), which were selected and pre-tested in previous research projects, was realized. The impact of such disturbing factors as airborne dust (coal, stone, lime and mixed dust), changes in temperature and humidity on the propagation of ultrasonic waves, amplitude and measurement accuracy was investigated. The tests were preceded by theoretical analysis. It was found that the transducers selected for the tests had a sufficient accuracy and range, so they can be used in the devices planned to be designed, allowing for the determining of the location of a roadheader in hard coal mine roadways, taking into account technical and legal restrictions. It was also specified which disturbing factors should be compensated and what methods and parameters of this compensation should be used.
\end{abstract}

Keywords: ultrasonic transducers; distance measuring; indoor locating system; RTLS; coal mine; roadheader; roadway; coal dust; stone dust; humidity

\section{Introduction}

The requirements of reducing the manufacturing costs, increasing the efficiency, as well as improving people's working conditions and limiting their presence in risk zones make it necessary to look for new solutions, often based on automation, not only in industrial production enterprises [1,2], but also in the mining industry [3]. Increasing the degree of automation in hard coal mines where various types of threats to the safety of employees are present is one of the issues requiring intensive studies, but special technical and legal requirements mean that solutions from other industries, and even from the mining industry, cannot be easily implemented $[4,5]$. Issues related to the system being developed that allows for precise determination of the position and orientation of the mining roadheader during drilling of roadways in a hard coal mine are this article's subject. The expected accuracy should allow to control the operation of the roadheader in terms of maintaining the proper direction and advance, at a distance of the measuring system from a roadheader not exceeding $30 \mathrm{~m}$. The system should be easy and quick to install, allowing to work without having to be moved during a work shift, while meeting the technical and legal requirements for operating in hard coal mines. Such a system can be classified as an example of the real-time locating system (RTLS), a class of systems that allow the determination of the position of objects in a specific environment or building, usually based on the transmission of radio waves, ultrasound or lasers [6,7]. The principle of a typical RTLS operation is most often based on one or more of the common algorithms, such as RSS (received signal strength), TOA (time of arrival), TDOA (time difference of arrival), POA 
(phase of arrival), NFER (near-field electromagnetic ranging), AOA (angle of arrival), DOA (direction of arrival) or dead reckoning [8,9]. Due to the expected ease of installation and operating conditions of the system, it was decided to focus on the methods for determining location by precisely measuring distances rather than angles or other parameters.

The preliminary stage of the work on the system for determining the location in the conditions of a hard coal mine, including the development of a method for the precise determination of distances in these conditions, was presented in our previous article [10]. It includes:

- Review and analysis of working conditions, technical requirements and limitations, as well as legal ones, relating to devices intended for operation in hard coal mines;

- Analysis of available solutions that are currently used in mining and can potentially be adapted to the requirements of the planned application;

- Review of the methods for determining the location and distance as well as measurement algorithms;

- Assessment of suitability of the available methods and devices for the expected application through SWOT (strengths, weaknesses, opportunities, threats) analysis;

- Theoretical analysis of the properties of ultrasonic waves initially selected as a technology that can meet the requirements of the expected application;

- Selection of the type and parameters of ultrasonic transducers to be used in the developed system;

- Design of a testing facility for distance measurements with the use of ultrasonic transducers;

- Preliminary tests of ultrasonic transducers;

- A full cycle of distance measurement tests with the use of selected ultrasonic transducers, including operation at the expected distances without disturbances and with simulated forced airflow in the ultrasound propagation environment.

The tests showed the legitimacy of using ultrasonic technology to determine the location in a hard coal mine [10]. The theoretical analysis of the ultrasonic wave propagation properties and the measurement results indicated the direction of further work: determination of the impact of various disturbing factors, the presence of which is typical for operation in coal mines, on the results obtained. Thanks to this, it is possible to prepare design assumptions for the developed equipment and measurement methods and to suggest appropriate algorithms that allow for the introduction of corrections to eliminate disturbances resulting from the work environment, when required.

\section{Analysis of Limitations, Theoretical Basis, Devices and Results of Previous Research}

Technical solutions allowing for the precise determination of distances and, subsequently, the location of objects in the conditions of a hard coal mine are limited both by technical factors depending on this specific environment, as well as by legal factors.

The main technical obstacles that may affect the ability to measure distance in hard coal mines are [11-15]:

- Mechanical barriers between the points, whose distance is measured, block, weaken or reflect the signals used for measuring the distance-machine components and equipment, ventilation ducts, pipelines, etc.;

- Reflections of the signals used for measurement in the roadway: measurement of the distance in long and narrow tunnels comes with the risk of reflections of these signals from the walls, floor and roof of the tunnel, which are additionally not smooth-roadway components, cables, pipes, etc.;

- Movement of air during forced ventilation-it may have a significant impact on the accuracy of measurements in some technologies, depending on the direction and speed of airflow; the expected average airflow rate around the roadheader should not exceed $1 \mathrm{~m} / \mathrm{s}$; 
- $\quad$ Dust generated by working roadheader, spread by the forced ventilation; the maximum dust concentration should not exceed $100 \mathrm{mg} / \mathrm{m}^{3}$, the highest concentration of dust is in the area of cutter head operation [16];

- Local changes of temperature can also change the signal propagation; it is suggested to assess the impact of temperature changes on the distance measuring accuracy in order to calibrate and compensate this impact; expected temperature in a hard coal mine varies from 10 to $40{ }^{\circ} \mathrm{C}$;

- High or variable relative air humidity, caused by water spraying required in the technological process [17], which may affect the accuracy of distance measurements or cause degradation of measuring devices;

- Vibrations and noise, which may affect the components of the measuring system, which require the use of technologies resistant to these phenomena or appropriate insulation or shock absorption of the fixation of the measuring device;

Most of the legal restrictions stem from coal mining safety requirements $[12,13,18]$ :

- The ban on certain technologies (e.g., high energy lasers);

- The ban on direct use of some materials/technologies, which can be used only if appropriately encased, which, however, can, e.g., limit the range of signal transmission;

- $\quad$ All devices must meet dust- and water tightness requirements and be approved for operation in the conditions of explosion hazard.

The analysis presented in [10] showed that among the different technologies used for automatic non-contact distance measurement, the determination of the distance by measuring the propagation of ultrasonic signals should meet the technical and legal requirements of the planned application. Technologies based on radio frequency signals can be difficult to apply at short distances (assuming planned application in coal mines), and laser technologies do not always meet legal requirements and are also more sensitive to vibration and dust.

By the definition, the ultrasonic wave is the vibration of the elastic medium particles, propagating in the form of a longitudinal wave [19], that can be affected by the environment composition heterogeneity (e.g., the difference in density or temperature, foreign particles inclusions (e.g., dust, water drops) and transmission medium movements.

\subsection{Selected Properties of Ultrasonic Waves Propagation}

Propagation velocity and attenuation of the medium are the most important parameters of the gaseous medium in which the ultrasonic waves propagate. The speed of the ultrasonic wave in gases is given by Equation (1) [19]:

$$
v_{U S}=\sqrt{\frac{\kappa(T) p_{0} T}{\rho_{0} T_{293}}}\left[\frac{\mathrm{m}}{\mathrm{s}}\right],
$$

where: $\rho_{0}$-gas density in normal conditions, $p_{0}$-gas pressure in normal conditions, $T$-gas temperature $[\mathrm{K}], T_{293}=293[\mathrm{~K}], \kappa(T)$-dimensionless adiabatic exponent equal to $c_{p} / c_{v}, c_{p}$-specific heat at constant pressure, $c_{v}$-specific heat at constant volume.

The coefficient $\kappa(T)$ depends on the temperature, but to a small extent also on the pressure of the gaseous medium. Within the range of typical air pressure $(810-1216 \mathrm{hPa})$, it has a constant value $\left(1.4\right.$ in the air at $\left.20^{\circ} \mathrm{C}\right)$. Thus, it can be assumed that the speed of propagation of ultrasonic waves in air does not depend on the air pressure, as long as it is within the typical atmospheric pressure range.

The speed of ultrasonic wave in the air depends on the air temperature: the higher the air temperature is, the faster its particles move $[19,20]$. The temperature coefficient of the sound velocity $v_{U S}(T)$ is similar to the linear velocity coefficient (in the temperature range from -5 to $100{ }^{\circ} \mathrm{C}$ ), thus it can be expressed as a derivative of velocity in relation to 
temperature. Assuming the linear form of the $v_{U S}(T)$ curve, Equation (1) can be transformed into (2) $[19,21]$ :

$$
v_{U S}=v_{U S O}+b T=v_{U S 0}\left(1+b^{\prime} T\right)\left[\frac{\mathrm{m}}{\mathrm{s}}\right],
$$

where: $v_{U S 0}$-speed of sound at $T_{0}=0{ }^{\circ} \mathrm{C}, b$-temperature coefficient of the speed of sound equal to $\Delta v_{U S} / \Delta T$ in relation to $T_{0}, b^{\prime}$-relative temperature coefficient of the speed of sound, $b^{\prime}=b / v_{\text {US0 }}, T$-temperature $\left[{ }^{\circ} \mathrm{C}\right]$.

Thus, the authors of $[19,20]$ proposed Equation (3).

$$
v_{U S}=331.85(1+0.00183 T)\left[\frac{\mathrm{m}}{\mathrm{s}}\right] \text {, }
$$

where: $\mathrm{T}$-temperature $\left[{ }^{\circ} \mathrm{C}\right]$.

For further work, the concept of measurements was adopted, in which, simultaneously with the sending of an ultrasonic pulse, a radio frequency (RF) signal will be sent, used for synchronization-determining the moment of the beginning of the measurement of the signal transmission time. In fact, the time difference between receiving radio and an ultrasonic pulse will be measured. The justification for this assumption is given in the next paragraphs.

It was assumed that the acoustic wave will be sent as a short pulse, and the moment of receiving the wavefront (the wave that has traveled the shortest path without obstacles-line of sight method [22-24]) will be detected. Thanks to this, the impact of reflections of ultrasonic waves on obstacles (like walls of a tunnel) will be excluded [20].

The distance between the transmitter and receiver of ultrasonic waves relative to RF wave is given by Equation (4) [25]:

$$
d=\Delta t \frac{v_{R F} \cdot v_{U S}}{v_{R F}-v_{U S}}[\mathrm{~m}]
$$

where: $\Delta t$-time difference between receiving both signals in the receiver, $v_{U S}-$ ultrasonic wave propagation speed, $v_{R F}-\mathrm{RF}$ wave propagation speed.

The speed of an RF wave is about one million times greater than that of a sound wave, a sound wave moves $20 \mathrm{~m}$ in about $58.8 \mathrm{~ms}$ (assuming $v_{U S}=340 \mathrm{~m} / \mathrm{s}$ ), while an RF wave travels the same distance in about $7 \mathrm{~ns}$. Neglecting the RF propagation time, Equation (4) can be simplified to the form given in Equation (5) [26]:

$$
d=v_{U S} \cdot \Delta t[\mathrm{~m}] \text {. }
$$

\subsection{Initial Results of Ultrasonic Wave Propagation Measurements}

Subsequently, in [10], the available sensors and ultrasonic transducers were reviewed. In the result the following specific devices were selected as the transmitter and receiver of ultrasonic waves: ultrasonic transducers AR30 and AR41, manufactured by AIRMAR for distance measurements in an air medium [27].

Parameters of the selected ultrasonic transducers:

- $\quad$ Resonance frequency-AR30: $30 \mathrm{kHz}, \mathrm{AR} 41: 41 \mathrm{kHz}$

- Transmitter sound pressure level-AR30: $105 \mathrm{~dB}, \mathrm{AR} 41: 110 \mathrm{~dB}$

- $\quad$ Receiver sensitivity-AR30: $-155 \mathrm{~dB}, \mathrm{AR} 41$ : $-160 \mathrm{~dB}$

- Maximum transmitter excitation signal voltage (peak to peak)—AR30: 2200 V, AR41: $1800 \mathrm{~V}$

The test stand included the following modules:

- $\quad 30 \mathrm{kHz} / 41 \mathrm{kHz}$ signal generator with signal parameters adjustment system;

- Ultrasonic transmitting transducer and ultrasonic receiving transducer (identical devices can be used in both roles);

- $\quad$ Receiving system with adjustable signal gain;

- Time-of-arrival (TOA) measurement system converting the ultrasonic wave propagation time between the transmitter and the receiver into a distance between these elements. 
During the test, two pairs of transducers (AR30 and AR41) were used as transmitters and receivers of ultrasonic waves. Both types of transducers (two pairs of AR30 and AR14) were used in tests and connected to the T1 module [27]. The transmitting section of the T1 module allows adjusting the frequency and voltage amplitude (in the range 200-500 V- $V_{p-p}$ - peak-to-peak voltage) applied to the transducer. The receiver enables amplification $(0,20,40,60 \mathrm{~dB})$ of the signal from the ultrasonic transducer. The amplified signal was recorded by a TDS2024B oscilloscope.

Initially, converters and testing instruments were tested [10]. The receiver and transmitter were placed in the corridor (as in the planned work environment of the designed system), and their distance varied from 5 to $40 \mathrm{~m}$. Measurements were taken at standard atmospheric pressure, the temperature of about $20^{\circ} \mathrm{C}$ and in the absence of additional disturbing factors (air movement, physical obstacles along the signal path). As expected, it was found that the amplitude of the received signals decreases with the distance between the transmitter and the receiver, the effective range of transducers operating at higher frequencies is smaller, however, both types of devices allow to work at a range sufficient for the planned application: AR41: $30 \mathrm{~m}$, AR30: $35 \mathrm{~m}$.

The propagation time of the ultrasonic wave as a function of the distance between the transmitting and receiving transducers were also checked. The measured propagation time at a constant measuring distance was also constant. The propagation time for both types of ultrasonic transducers was the same. The relationship between distance and propagation time is linear, thus it can be concluded that in constant atmospheric conditions the measurement distance is directly proportional to the propagation time of ultrasonic waves.

Then, the impact of selected disturbances on the propagation time of the ultrasonic signal was tested. It was decided to determine the impact of air movement in the measurement path, generated by fans, and the direction of air movement could be consistent or opposite to the direction of ultrasound propagation. The tests were carried out multiple times at distances from 5 to $20 \mathrm{~m}$, every $5 \mathrm{~m}$.

It was confirmed that disturbances of the ultrasound propagation medium (air movements) have a much greater impact on the amplitude of the received signal than on the time of wave propagation. The results indicated that the maximum relative change in the voltage amplitude was $163 \%$, while the maximum change in the propagation time measurement caused by air movement was $0.3 \%$. Thus, if the airflow speed in a coal mine roadway reaches the maximum value of $1 \mathrm{~m} / \mathrm{s}$, propagation time measurement uncertainty up to $0.3 \%$ can be expected [10].

\section{Testing the Impact of Dust Concentration on the Propagation Time of Ultrasonic Waves}

The most important factor accompanying the rock mining process is dust. It is a harmful factor in a hard coal mine for many reasons [28,29]. It reduces visibility, can be explosive, and additionally, the respirable fraction [30] is harmful to human health. The aim of the test was to determine the impact of dust concentration on the propagation parameters of ultrasonic waves, mainly the propagation time, as a parameter used to measure the distance in the developed method of underground positioning. The new test stand was built, the block diagram of which is shown in Figure 1.

The measuring system consists of a closed tunnel (a) with a cross-sectional dimension of $0.75 \times 1 \mathrm{~m}$ and a length of $4 \mathrm{~m}$, in which ultrasonic waves propagated and dust of controlled concentration was generated. On one side of the tunnel (a) there was an air injection installation (b) consisting of a blow-out nozzle (e) to which compressed air was connected via a compressed air supply hose (g). The airflow was controlled by a manual valve (f).

Air-dust mixture was generated by attaching a dust dispenser to the blowing nozzle (e), which consisted of a dust container (h) with a mechanical agitator and valve, a screw feeder (m) and a controller (i) allowing for regulation of the valve opening, and, hence, the control of the percentage amount of dust dispensed. The nozzle of the screw feeder $(\mathrm{m})$ 
was located at the end of the blow nozzle (e) through which the air was injected into the tunnel (a).

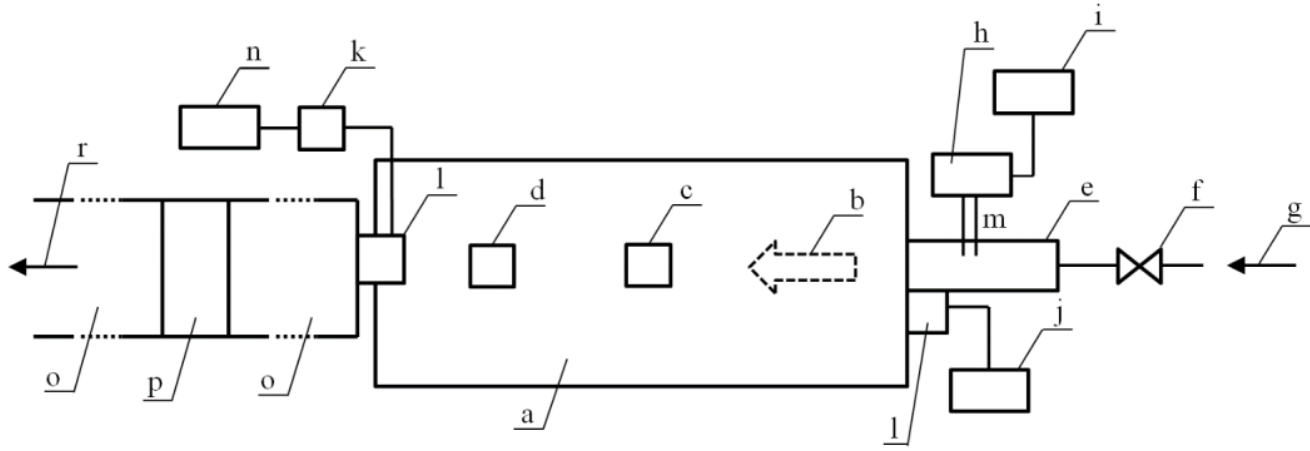

Figure 1. Diagram of the test stand designed for research on the impact of dust concentration on the propagation of ultrasonic waves; a-measuring tunnel, b-direction of airflow, c-anemometer, $\mathrm{d}$-dust meter, e-blow-out nozzle, f-valve, g-compressed air supply, h-dust container with agitator and valve, $\mathrm{i}$-controller, $\mathrm{j}$ - transmitter module, $\mathrm{k}$-receiver module, $\mathrm{l}$-ultrasonic transducer, $\mathrm{m}$-screw feeder, $\mathrm{n}$ - portable computer, $\mathrm{o}$ - air extraction pipe, $\mathrm{p}$-fan, $\mathrm{r}$ - air outlet to the outside.

On the other side of the tunnel (a), an air extraction pipe (o) was installed, through which the air/dust mixture flowing through the tunnel (a), by a fan (p), was transported outside the measuring station (r). At both ends of the tunnel (a), ultrasonic transducers (l) were installed, connected to the transmitter or receiver of ultrasonic waves ( $j$ and $k$, interchangeably), which made it possible to change the direction of ultrasonic waves propagation during the tests. The distance between the transmitter and receiver was $4 \mathrm{~m}$.

In the middle of the tunnel (a) cross-section, halfway along its length, an air velocity meter-anemometer (c) was installed. At the end of the tunnel (a), on the outlet side, a dust concentration measuring device (d) was set. Measurement data from the receiver module (k) were sent via a serial bus to the computer (n), where they were recorded and analyzed. The external and internal view of the station are presented in Figure 2.
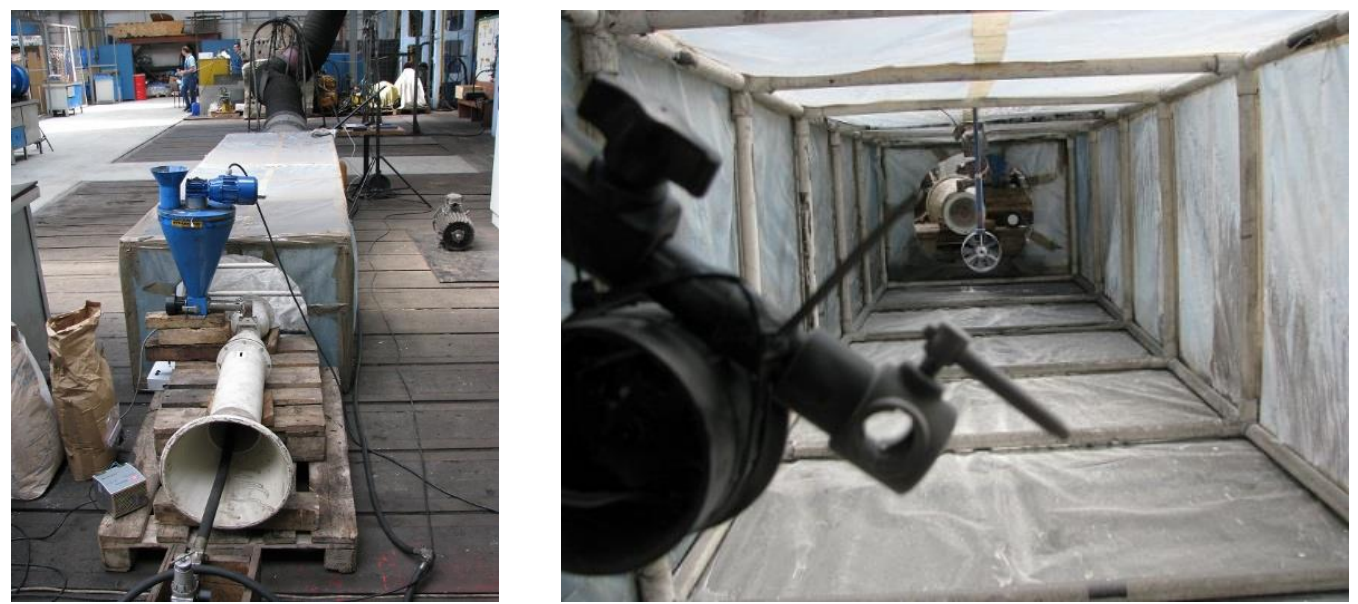

Figure 2. Photos of the test stand for measuring the impact of dust concentration on the propagation of ultrasonic waves.

The measurements were realized by using pairs of both types of transducers: AR30 and AR41, with the propagation of ultrasonic waves in two directions: along and opposite to the direction of the airflow. For this purpose, the places of transmitter and receiver modules $(j, k)$ were changed.

The amount of dust was determined from dust concentration measured by the CIP-10 gravimetric dust meters [31]. The concentration of total dust was measured during all tests, 
while in selected samples a second dust meter was used, measuring only the concentration of the respirable fraction.

During the test, three types of measurements were taken: (I) without the disturbances from external factors (air movement and dust), hereinafter referred to as "background" measurements, (II) with the flow of dust-free air, marked on the charts as $0 \%$, and (III) with airborne dust, indicated by the percentage setting of the dust feeder controller. In the analyses, measurements from two dust feeder capacities $-50 \%$ and $100 \%$-were considered.

Four types of dust were used during the tests:

- Stone dust, from the drilling of a roadway in a copper mine;

- Coal dust;

- Limestone dust, typically used as an extinguishing agent (explosion barrier) in hard coal mines;

- A mixture of stone and coal dust.

As the dust feeder controller only had a percentage regulation of the valve opening, before each series of measurements, the amount of dust mass dosed for 1 minute was determined empirically. On this basis, using the following Equation (6), the expected dust concentration in the measuring tunnel was calculated:

$$
C=\frac{m_{m} \cdot \frac{l}{60 v_{p}} \cdot 10^{-3}}{V}\left[\frac{\mathrm{kg}}{\mathrm{m}^{3}}\right]
$$

where: $m_{m}$-mass of dust fed per minute, $l$-length of the measuring tunnel, $v_{p}$-airflow speed, $V$-the volume of the measuring tunnel.

Airflow during the tests was $1 \mathrm{~m} / \mathrm{s}$. View of dust level during the tests, at different concentrations and types of dust, is shown in Figure 3.

(a)

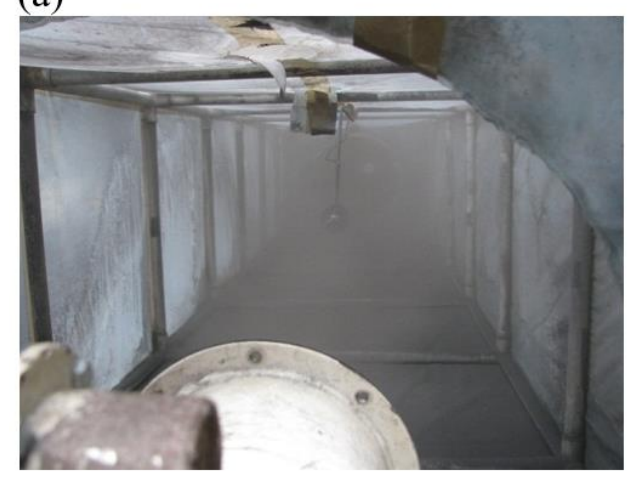

(c)

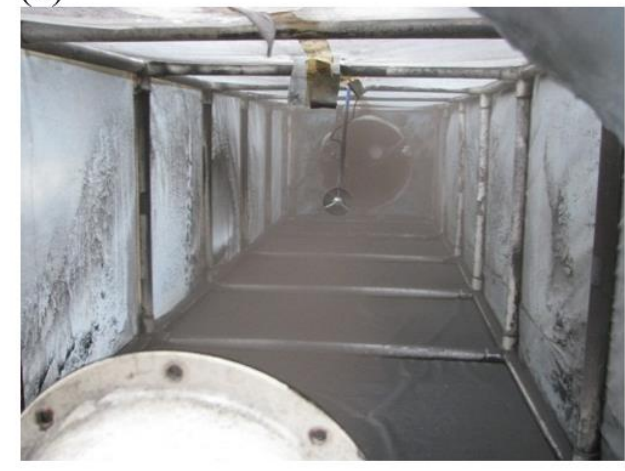

(b)

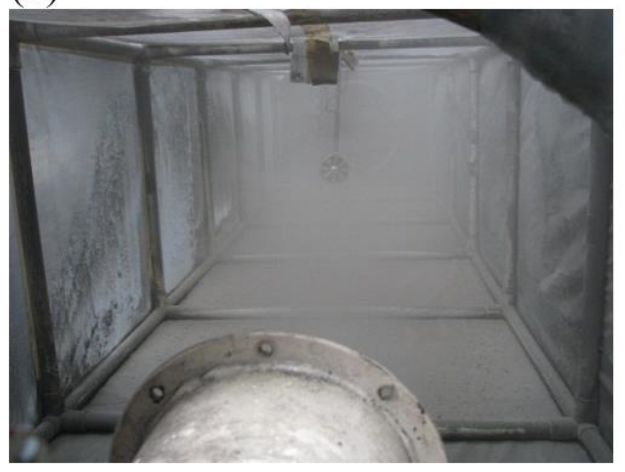

(d)

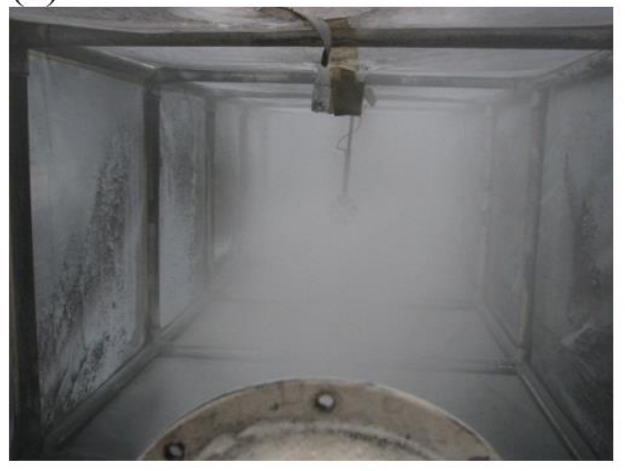

Figure 3. Dustiness in the tunnel during the tests: (a) stone and coal dust (50\%), (b) stone dust (100\%), (c) coal dust (50\%), (d) limestone dust (100\%). 
Measurements were made in a series of 30 samples taken with a time interval of $1 \mathrm{~s}$ ("Measurement series" mode). The results are presented in the form of graphs, arranged in terms of the type of transducer used and the direction of ultrasonic waves propagation.

\subsection{Measurements with the Use of the AR30 Transducer}

During testing the dust effect on the propagation times of $30 \mathrm{kHz}$ frequency ultrasonic waves, dust concentrations inside the test tunnel presented in Table 1 were used.

Table 1. Values of dust concentration inside the tunnel during tests with AR30 transducers.

\begin{tabular}{|c|c|c|c|c|c|}
\hline Type of the Dust & $\begin{array}{l}\text { Feeder } \\
\text { Controller } \\
\text { Setting }\end{array}$ & $\begin{array}{l}\text { The Amount of } \\
\text { Dust Fed per } \\
\text { Minute }\left[\mathrm{kg} \cdot 10^{-3}\right]\end{array}$ & $\begin{array}{c}\text { Calculated } \\
\text { Concentration } \\
{\left[\left(\mathrm{kg} \cdot 10^{-3}\right) / \mathrm{m}^{3}\right]}\end{array}$ & $\begin{array}{l}\text { Measured Dust } \\
\text { Concentration } \\
\text { (Total Dust) } \\
{\left[\left(\mathbf{k g} \cdot 10^{-3}\right) / \mathrm{m}^{3}\right]}\end{array}$ & $\begin{array}{c}\text { Measured Dust } \\
\text { Concentration } \\
\text { (Respirable Dust) } \\
{\left[\left(\mathrm{kg} \cdot \mathbf{1 0}^{-3}\right) / \mathrm{m}^{3}\right]}\end{array}$ \\
\hline \multirow{2}{*}{ Coal—stone (mixed) } & $50 \%$ & 95.6 & 2.1 & 0.601 & 0.159 \\
\hline & $100 \%$ & 155.0 & 3.4 & 1.105 & 0.233 \\
\hline \multirow{2}{*}{ Stone } & $50 \%$ & 126.0 & 2.8 & 0.843 & - \\
\hline & $100 \%$ & 218.0 & 4.8 & 1.229 & 0.197 \\
\hline \multirow{2}{*}{ Coal } & $50 \%$ & 77.4 & 1.7 & 0.608 & - \\
\hline & $100 \%$ & 117.0 & 2.6 & 0.928 & 0.170 \\
\hline \multirow{2}{*}{ Lime } & $50 \%$ & 122.0 & 2.7 & 1.263 & - \\
\hline & $100 \%$ & 197.6 & 4.4 & 1.816 & - \\
\hline
\end{tabular}

The dust concentration calculated from the amount of dust fed is higher than the dust concentration measured at the end of the tunnel. This is due to the fact that some of the dust has been deposited at the bottom of the tunnel. In further analysis, the values measured by dust meters were taken into account.

Figure 4 shows the graphs of the propagation time of ultrasonic waves at different dust levels and different types of dust. The direction of propagation of ultrasonic waves was consistent with the direction of airflow. The air temperature was $21^{\circ} \mathrm{C}$.

Figure 5 shows the propagation times of ultrasonic waves generated from the AR30 transducer with the propagation direction opposite to the airflow direction.

\subsection{Measurements with the Use of the AR41 Transducer}

During testing the dust effect on the propagation times of $41 \mathrm{kHz}$ frequency ultrasonic waves, dust concentrations inside the test tunnel presented in Table 2 were used.

Figure 6 shows the diagrams of the propagation time of ultrasonic waves at different dust levels. The direction of propagation of ultrasonic waves was consistent with the direction of airflow. The air temperature was $21^{\circ} \mathrm{C}$.

Figure 7 shows the diagrams of propagation times of ultrasonic waves generated from the AR41 transducer with the direction of propagation opposite to the direction of airflow.

\subsection{Analysis of the Results}

Analysis of the results began with a comparison of both tested types of transducers. Figure 8 shows the graphs of the measured propagation times of two types of ultrasonic transducers at maximum dustiness $(100 \%$ setting) and different directions of ultrasonic waves propagation.

Figure 9 compares the propagation times of ultrasonic waves in the presence of all types of dust and the airflow without dust. 
(a)

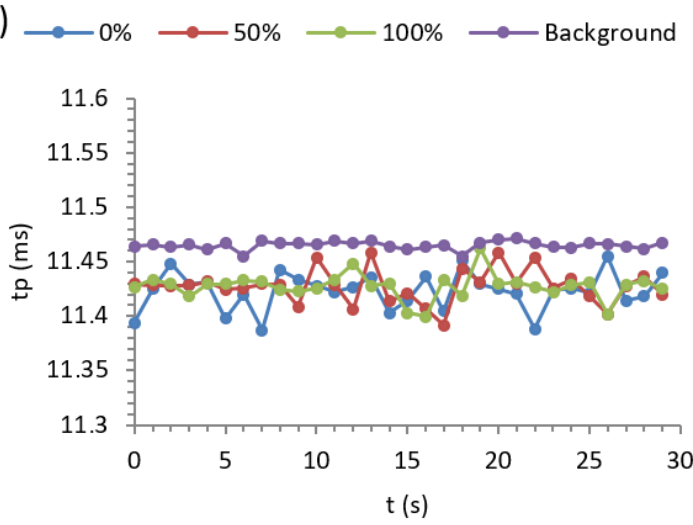

(c)

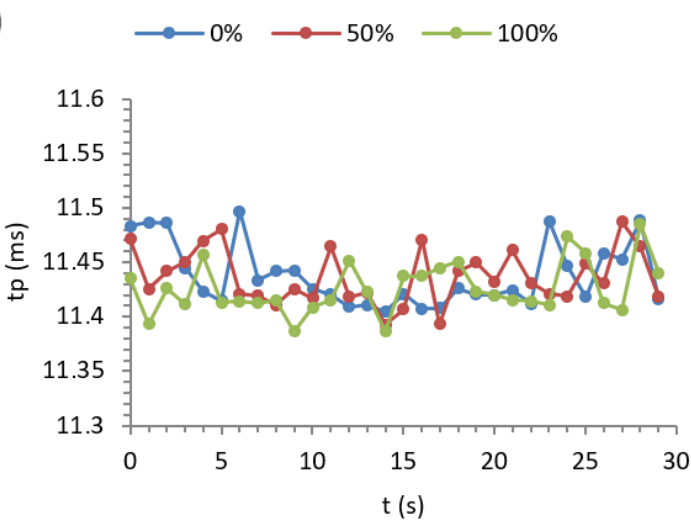

(b)

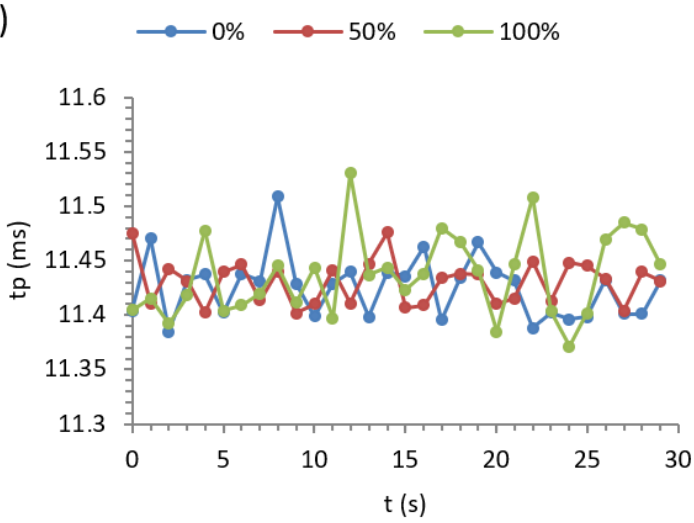

(d)

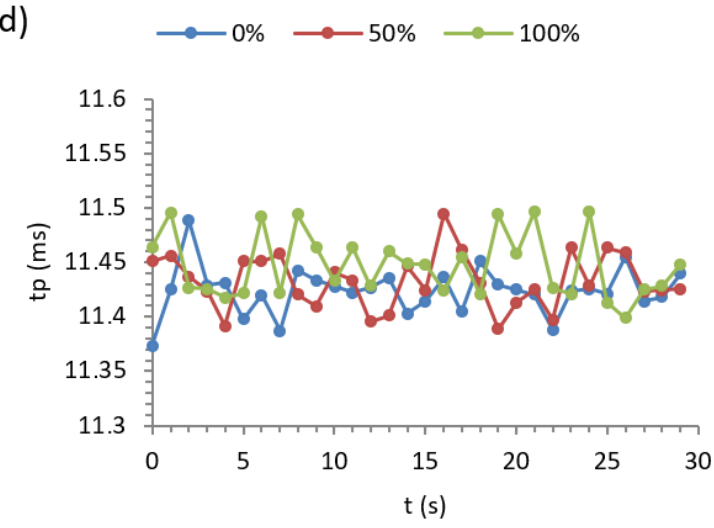

Figure 4. Graphs of the ultrasonic wave propagation time (AR30), with the direction of propagation following the direction of airflow: (a) coal dust, (b) stone dust, (c) coal-stone dust, (d) limestone dust.

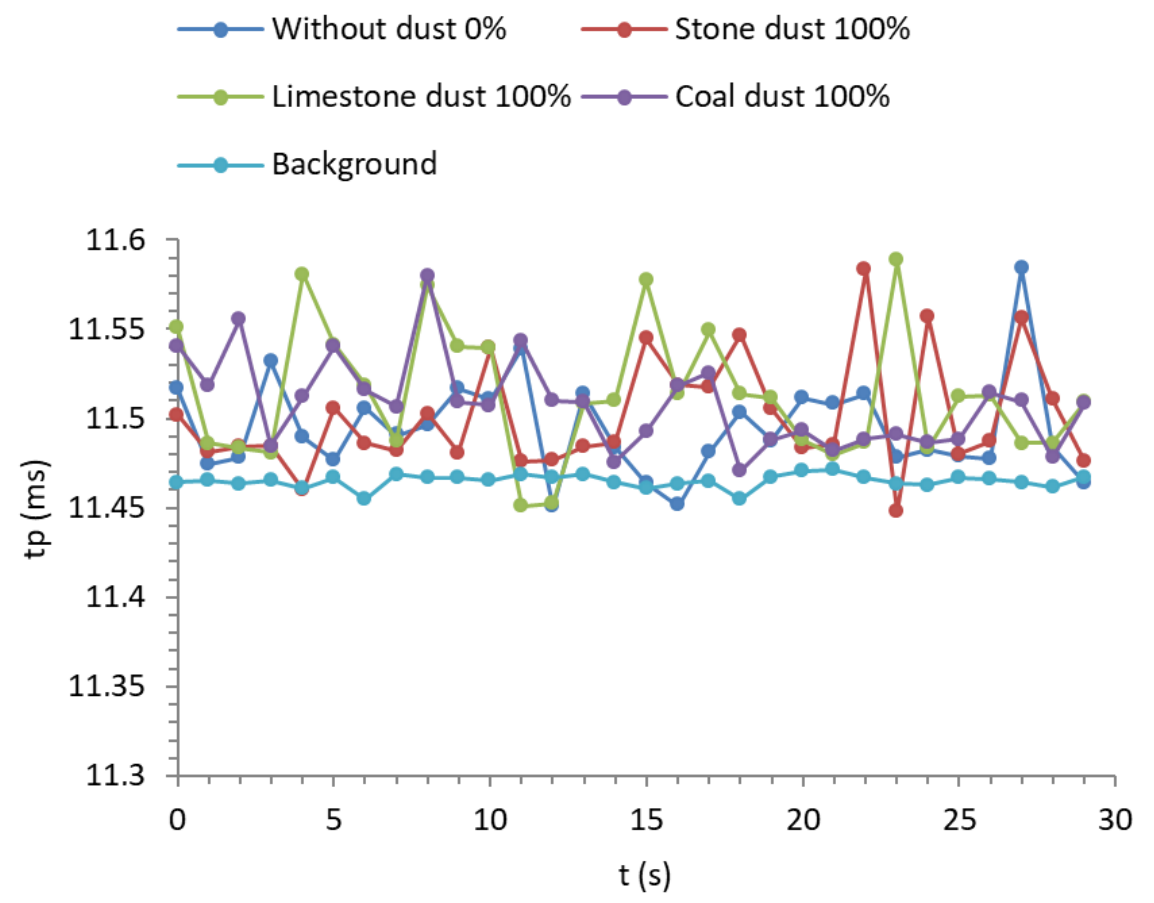

Figure 5. Graphs of the propagation time of ultrasonic waves (AR30) with the direction of propagation opposite to the direction of airflow, with the use of stone, coal and lime dust. 
Table 2. Values of dust concentration inside the tunnel during tests with AR41 transducers.

\begin{tabular}{|c|c|c|c|c|c|}
\hline Type of the Dust & $\begin{array}{l}\text { Feeder } \\
\text { Controller } \\
\text { Setting }\end{array}$ & $\begin{array}{l}\text { The Amount of } \\
\text { Dust Fed per } \\
\text { Minute }\left[\mathrm{kg} \cdot 10^{-3}\right]\end{array}$ & $\begin{array}{c}\text { Calculated } \\
\text { Concentration } \\
{\left[\left(\mathbf{k g} \cdot 10^{-3}\right) / \mathrm{m}^{3}\right]}\end{array}$ & $\begin{array}{c}\text { Measured Dust } \\
\text { Concentration } \\
(\text { Total Dust) } \\
{\left[\left(\mathbf{k g} \cdot 10^{-3}\right) / \mathrm{m}^{3}\right]}\end{array}$ & $\begin{array}{c}\text { Measured Dust } \\
\text { Concentration } \\
\text { (Respirable Dust) } \\
{\left[\left(\mathrm{kg} \cdot \mathbf{1 0}^{-3}\right) / \mathrm{m}^{3}\right]}\end{array}$ \\
\hline \multirow{2}{*}{ Coal-stone (mixed) } & $50 \%$ & 77.0 & 1.7 & 0.533 & - \\
\hline & $100 \%$ & 117.0 & 2.6 & 0.832 & - \\
\hline \multirow{2}{*}{ Stone } & $50 \%$ & 126.0 & 2.8 & 0.690 & - \\
\hline & $100 \%$ & 218.0 & 4.8 & 0.989 & - \\
\hline \multirow{2}{*}{ Coal } & $50 \%$ & 95.7 & 2.1 & 0.599 & - \\
\hline & $100 \%$ & 155.0 & 3.4 & 0.971 & - \\
\hline \multirow{2}{*}{ Lime } & $50 \%$ & 118.0 & 2.6 & 1.155 & - \\
\hline & $100 \%$ & 197.0 & 4.4 & 2.030 & 0.459 \\
\hline
\end{tabular}

(a)

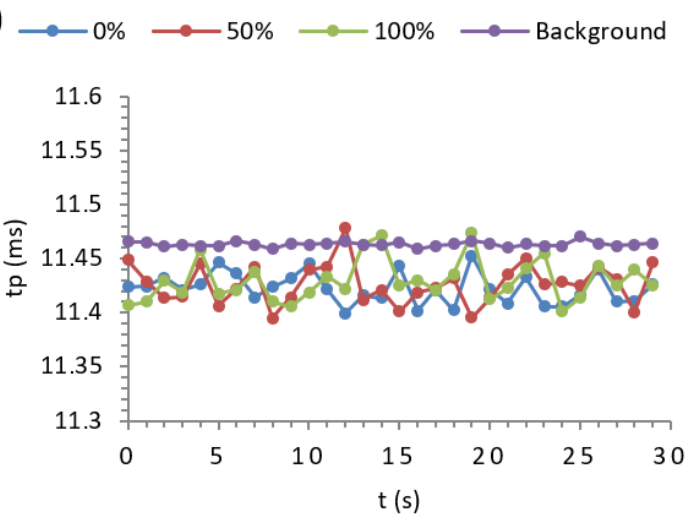

(c)

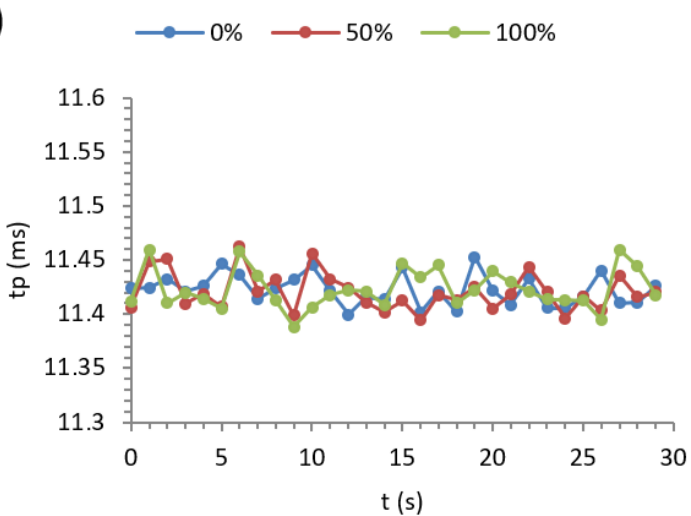

(b)

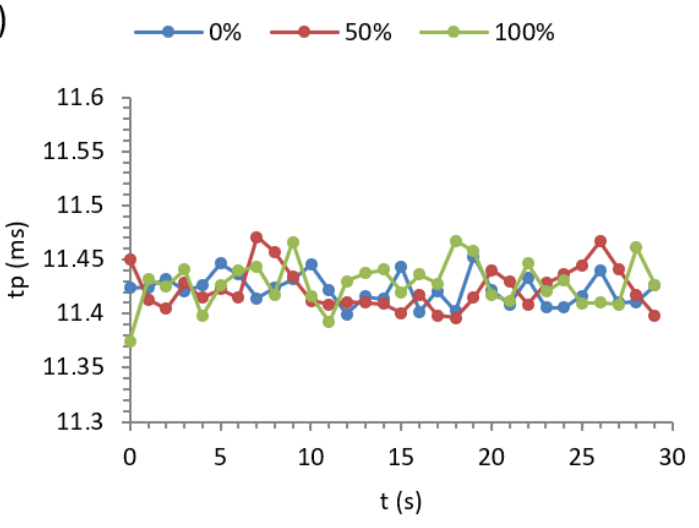

(d)

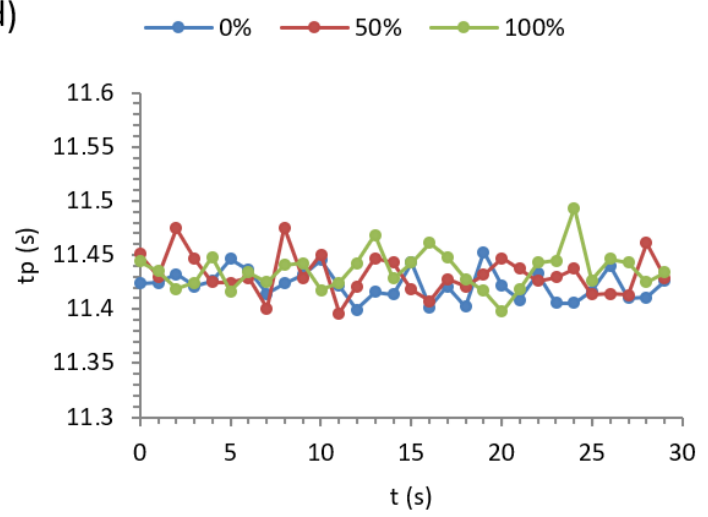

Figure 6. Graphs of the ultrasonic wave propagation time (AR41), with the propagation direction following the airflow direction: (a) coal dust, (b) stone dust, (c) coal-stone dust, (d) limestone dust. 
(a)

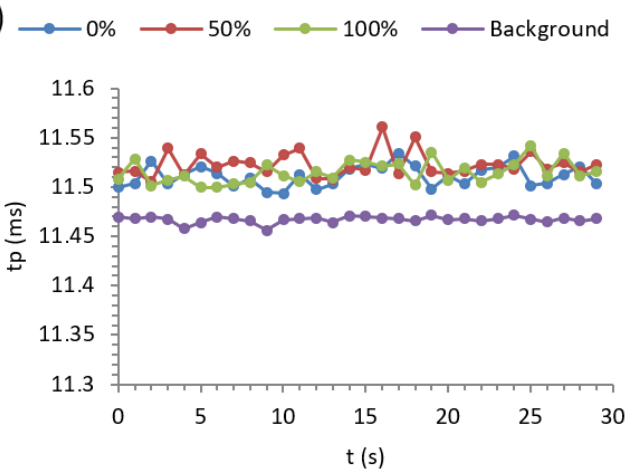

(c)

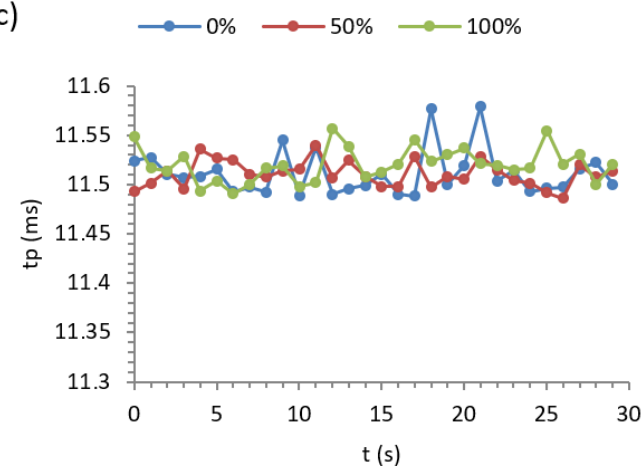

(b)

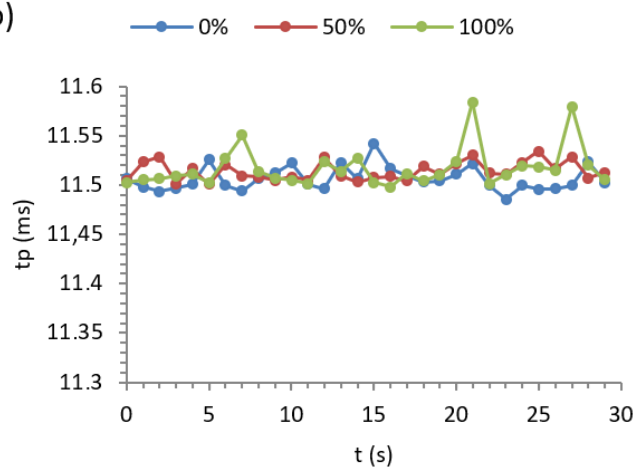

(d)

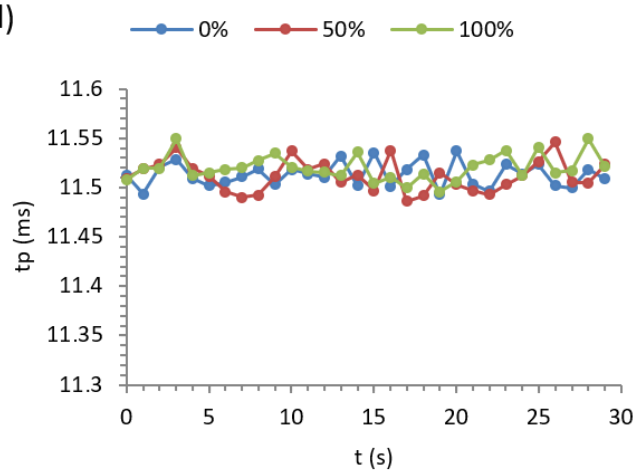

Figure 7. Graphs of the ultrasonic wave propagation time (AR41), with the direction of propagation opposite to the direction of airflow: (a) coal dust, (b) stone dust, (c) coal-stone dust, (d) limestone dust.

(a)

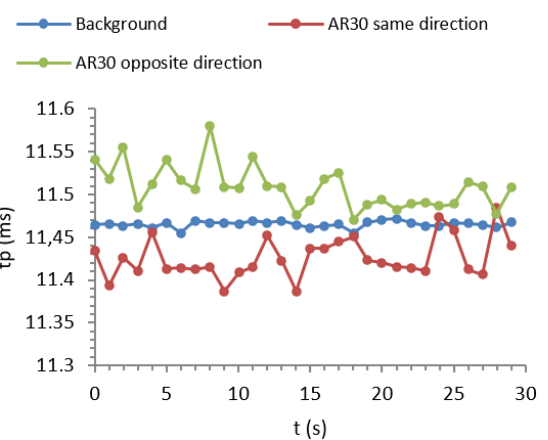

(c)

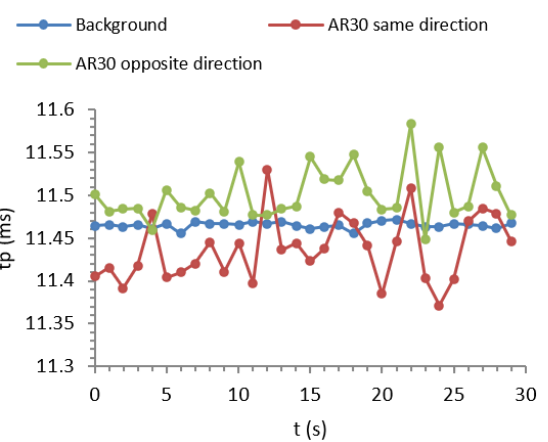

(b)

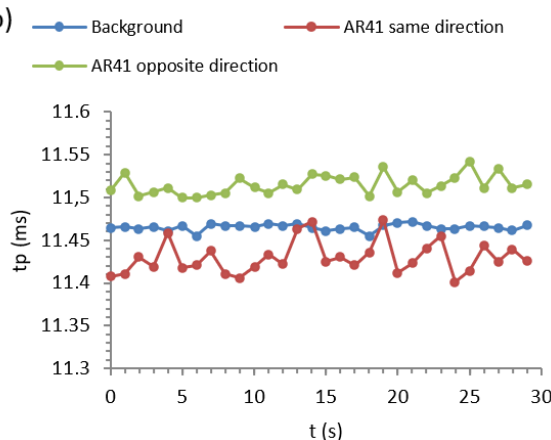

(d)

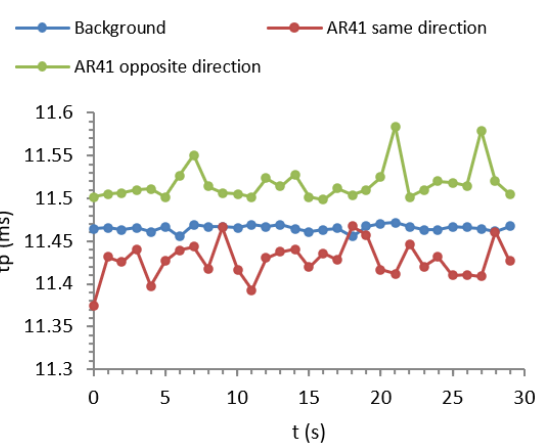

Figure 8. Graphs of the measured propagation times of ultrasonic waves, with maximum dustiness (100\% setting) and different directions of ultrasonic waves propagation: (a) coal dust and AR30 transducers, (b) coal dust and AR41 transducers, (c) stone dust and AR30 transducers, (d) stone dust and AR41 transducers. 


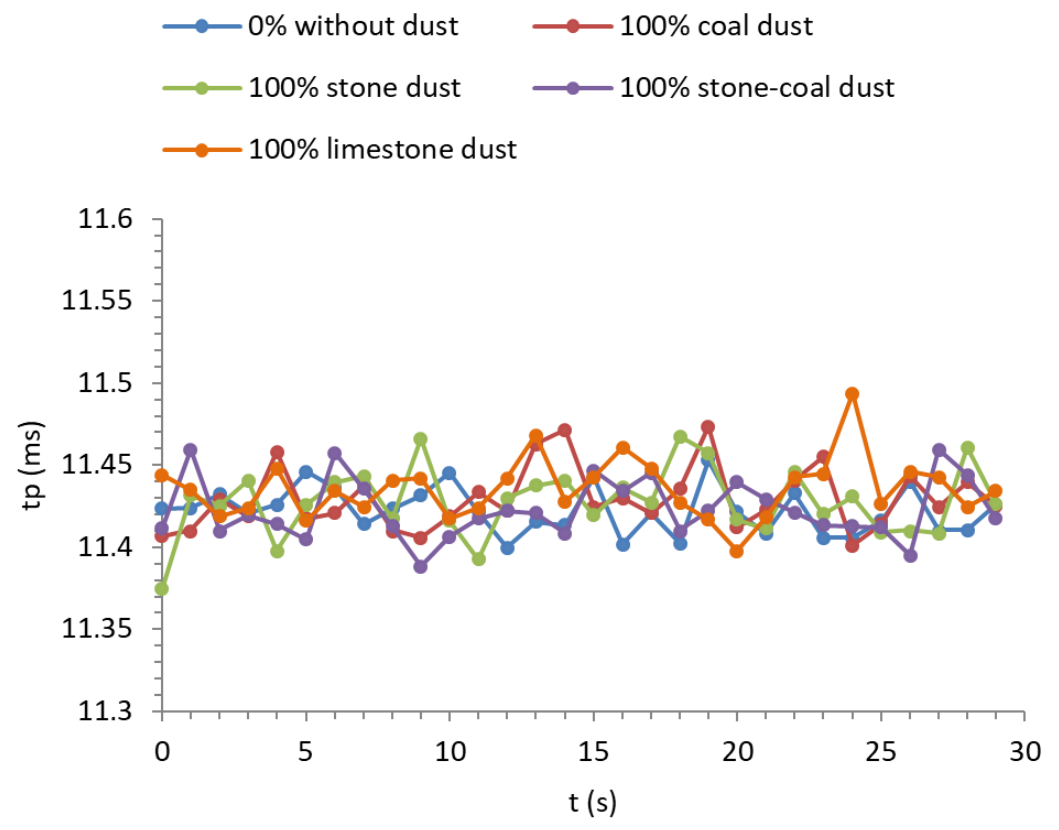

Figure 9. Ultrasonic wave propagation times for various types of dust, AR41 transducers and the wave propagation direction consistent with the airflow.

Table 3 presents the errors in measuring the propagation time of ultrasonic waves in relation to the background measurement (without airflow and without dust) recorded in all measurement series for the AR30 transducer, and in Table 4 the corresponding data for the AR41.

Table 3. Values of errors and uncertainties in measuring the propagation time of ultrasonic waves-AR30.

\begin{tabular}{|c|c|c|c|c|c|c|}
\hline $\begin{array}{c}\text { Direction of } \\
\text { Propagation of } \\
\text { Ultrasound Waves }\end{array}$ & $\begin{array}{c}\text { Type of the } \\
\text { Dust }\end{array}$ & $\begin{array}{c}\text { Feeder } \\
\text { Controller } \\
\text { Setting } \\
\end{array}$ & $\begin{array}{c}\text { Average Value } \\
\text { of Propagation } \\
\text { Time }\left[s \cdot 10^{-3}\right]\end{array}$ & $\begin{array}{c}\text { Maximum } \\
\text { Relative Error } \\
{[\%]}\end{array}$ & $\begin{array}{c}\text { Average } \\
\text { Relative Error } \\
{[\%]}\end{array}$ & $\begin{array}{c}\text { Standard } \\
\text { Deviation }\end{array}$ \\
\hline \multirow{12}{*}{ Parallel Flow } & \multirow{3}{*}{ Coal-stone } & $0 \%$ & 11.423 & 0.68 & 0.37 & 0.017 \\
\hline & & $50 \%$ & 11.427 & 0.64 & 0.33 & 0.016 \\
\hline & & $100 \%$ & 11.427 & 0.57 & 0.33 & 0.012 \\
\hline & \multirow{3}{*}{ Stone } & $0 \%$ & 11.425 & 0.70 & 0.38 & 0.028 \\
\hline & & $50 \%$ & 11.430 & 0.55 & 0.32 & 0.020 \\
\hline & & $100 \%$ & 11.437 & 0.82 & 0.35 & 0.037 \\
\hline & \multirow{3}{*}{ Coal } & $0 \%$ & 11.438 & 0.53 & 0.32 & 0.029 \\
\hline & & $50 \%$ & 11.439 & 0.81 & 0.30 & 0.030 \\
\hline & & $100 \%$ & 11.458 & 0.68 & 0.36 & 0.023 \\
\hline & \multirow{3}{*}{ Lime } & $0 \%$ & 11.424 & 0.80 & 0.38 & 0.022 \\
\hline & & $50 \%$ & 11.433 & 0.66 & 0.30 & 0.025 \\
\hline & & $100 \%$ & 11.447 & 0.58 & 0.26 & 0.029 \\
\hline \multirow{4}{*}{ Counterflow } & - & $0 \%$ & 11.495 & 1.04 & 0.28 & 0.027 \\
\hline & Stone & $100 \%$ & 11.501 & 1.03 & 0.33 & 0.031 \\
\hline & Lime & $100 \%$ & 11.513 & 1.07 & 0.44 & 0.036 \\
\hline & Coal & $100 \%$ & 11.508 & 1.00 & 0.38 & 0.025 \\
\hline
\end{tabular}


Table 4. Values of errors and uncertainties in measuring the propagation time of ultrasonic waves-AR41.

\begin{tabular}{|c|c|c|c|c|c|c|}
\hline $\begin{array}{c}\text { Direction of } \\
\text { Propagation of } \\
\text { Ultrasound Waves }\end{array}$ & $\begin{array}{c}\text { Type of the } \\
\text { Dust }\end{array}$ & $\begin{array}{l}\text { Feeder } \\
\text { Controller } \\
\text { Setting }\end{array}$ & $\begin{array}{c}\text { Average value } \\
\text { of Propagation } \\
\text { Time }\left[s \cdot 10^{-3}\right]\end{array}$ & $\begin{array}{c}\text { Maximum } \\
\text { Relative Error } \\
{[\%]}\end{array}$ & $\begin{array}{c}\text { Average } \\
\text { Relative Error } \\
{[\%]}\end{array}$ & $\begin{array}{c}\text { Standard } \\
\text { Deviation }\end{array}$ \\
\hline \multirow{9}{*}{ Parallel Flow } & - & $0 \%$ & 11.423 & 0.55 & 0.36 & 0.014 \\
\hline & \multirow{2}{*}{ Coal } & $50 \%$ & 11.426 & 0.60 & 0.33 & 0.018 \\
\hline & & $100 \%$ & 11.430 & 0.54 & 0.30 & 0.019 \\
\hline & \multirow{2}{*}{ Stone } & $50 \%$ & 11.423 & 0.58 & 0.35 & 0.020 \\
\hline & & $100 \%$ & 11.428 & 0.78 & 0.31 & 0.020 \\
\hline & \multirow{2}{*}{ Coal-stone } & $50 \%$ & 11.421 & 0.60 & 0.37 & 0.018 \\
\hline & & $100 \%$ & 11.423 & 0.65 & 0.35 & 0.018 \\
\hline & \multirow{2}{*}{ Lime } & $50 \%$ & 11.432 & 0.58 & 0.29 & 0.019 \\
\hline & & $100 \%$ & 11.436 & 0.57 & 0.26 & 0.018 \\
\hline \multirow{12}{*}{ Counterflow } & \multirow{3}{*}{ Coal } & $0 \%$ & 11.511 & 0.58 & 0.38 & 0.011 \\
\hline & & $50 \%$ & 11.523 & 0.82 & 0.49 & 0.012 \\
\hline & & $100 \%$ & 11.515 & 0.65 & 0.42 & 0.011 \\
\hline & \multirow{3}{*}{ Stone } & $0 \%$ & 11.506 & 0.65 & 0.34 & 0.012 \\
\hline & & $50 \%$ & 11.514 & 0.58 & 0.41 & 0.009 \\
\hline & & $100 \%$ & 11.517 & 1.02 & 0.43 & 0.020 \\
\hline & \multirow{3}{*}{ Coal-stone } & $0 \%$ & 11.511 & 0.97 & 0.38 & 0.022 \\
\hline & & $50 \%$ & 11.511 & 0.64 & 0.38 & 0.013 \\
\hline & & $100 \%$ & 11.520 & 0.78 & 0.46 & 0.017 \\
\hline & \multirow{3}{*}{ Lime } & $0 \%$ & 11.513 & 0.61 & 0.40 & 0.012 \\
\hline & & $50 \%$ & 11.512 & 0.69 & 0.39 & 0.015 \\
\hline & & $100 \%$ & 11.520 & 0.72 & 0.46 & 0.012 \\
\hline
\end{tabular}

Based on the graphs in Figures 4-7, it can be observed that the recorded values of the propagation time of ultrasonic waves have similar values for a given type of dust and the same direction of the propagation vector. This applies to the case with airborne dust of concentration described in Tables 1 and 2 (the feeder controller set at $50 \%$ and $100 \%$ ), as well as with non-dusted air, the average flow velocity of which was $1 \mathrm{~m} / \mathrm{s}$.

Moreover, in the case of different types of dust (Figure 9), the wave propagation time was at a similar level. However, a significant difference is caused by the direction of the ultrasonic wave propagation vector in relation to the airflow vector (Figure 8). This is due to changes in airflow velocity. This relationship was described in Section 2.1. According to the calculations, the flow velocity at the level of $1 \mathrm{~m} / \mathrm{s}$ causes an absolute error of propagation time measurement of about $0.036 \mathrm{~ms}$ over the length of $4 \mathrm{~m}$ (in the calculation of this error, the speed of sound propagation was assumed to be $334 \mathrm{~m} / \mathrm{s}$ ). The calculated value corresponds to the recorded differences, shown on the charts (Figure 8). The direction of the ultrasonic wave propagation vector consistent with the airflow vector reduces the measured time values, while the opposite-increases these values (Figure 8). Reference values called "background" were measured without any forced airflow.

A more detailed analysis was made possible by comparing the mean values of the propagation time, relative errors and standard deviation as a measure of the uncertainty, calculated on the basis of the series of measurements, in Table 4. Based on Table 4 and the graphs in Figures 4-7, it can be concluded that the measurements with the forced airflow are characterized by a much larger spread of values (measurement uncertainty) compared to the "background" measurements without the forced air movement. The maximum relative 
error of the measurements was about $1 \%$ and did not depend on the type of dust and its concentration. Moreover, the standard deviation did not depend on these parameters. It can therefore be concluded that the measurement uncertainty does not depend on the type of dust and its concentration, but it depends on the airflow velocity and its homogeneity, which was theoretically foreseen and investigated in our previous publication [10].

By analyzing the mean values and the averaged relative error from the measurement series, it is possible to show a slight increase in their values in the case of a dusty propagation medium, however, the differences are small, representing only fractions of a percent. The largest of the observed differences were in the case of limestone dust, which, however, is rare in hard coal during the normal mining operation. The dust levels used in the tests were at maximum, compared to the conditions that can be encountered in real conditions $[12,32,33]$. On this basis, it can be concluded that the concentration of dust in the atmosphere of the coal mine roadway will not have a significant impact on the measurements of the propagation time of ultrasonic waves.

\section{Testing the Impact of Temperature Changes on the Propagation Time of Ultrasonic Waves}

As the analysis carried out in Section 2.1 showed, the temperature is a factor that can have a noticeable effect on the speed of propagation of ultrasonic waves. For this reason, studies were carried out to determine the dependence of the propagation speed of ultrasonic waves on the temperature of the medium in which the wave is propagated (air). Figure 10 shows a diagram of the next developed test stand. Test tunnel (d) with a closed space was built for the tests to allow to simulate changing atmospheric conditions, in this part of the tests: variable temperature. Dimensions of the tunnel: rectangular base $4 \mathrm{~m} \times 2.2 \mathrm{~m}$, the height of the tunnel $1.9 \mathrm{~m}$. Inside the tunnel, there was a fixed platform (h), on which the transmitter module (e) and one of the ultrasonic transducers (c) were placed.

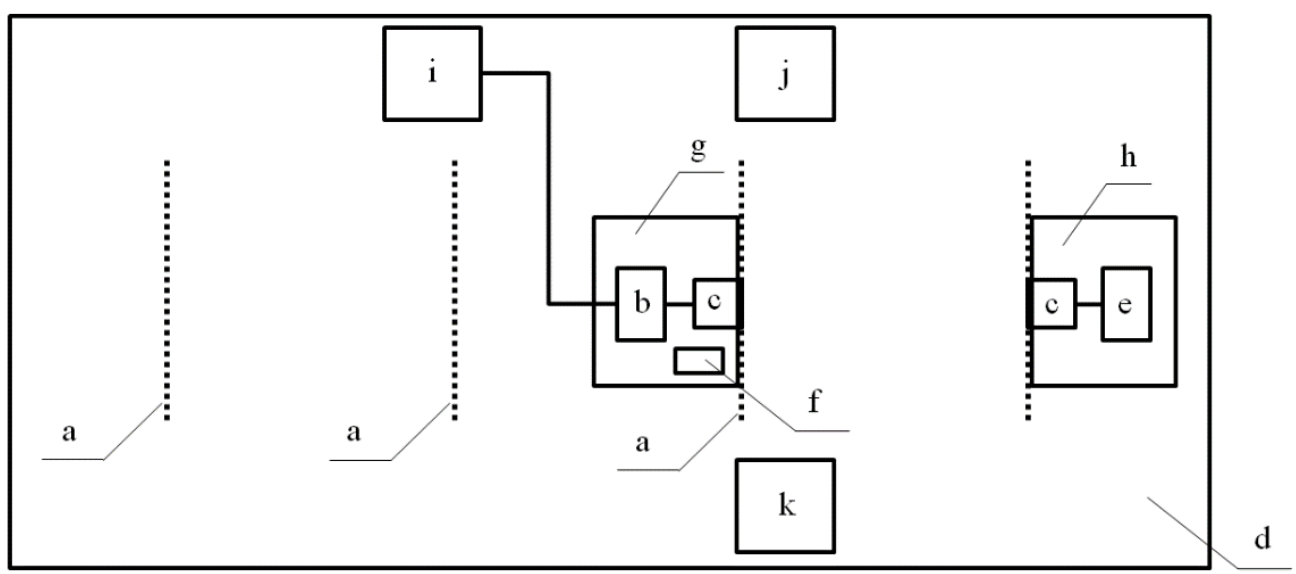

Figure 10. Diagram of test stand for testing the effect of temperature on ultrasound propagation velocity; a-measuring thresholds $(1,2,3 \mathrm{~m})$, b-receiver module, c-ultrasonic transducer, $\mathrm{d}$ - test tunnel space, e-transmitter module, f-thermometer, g-repositionable platform, h-fixed platform, $\mathrm{i}$-computer recording measurements, $\mathrm{j}$-gas heater, $\mathrm{k}$ - electric heater.

The receiving transducer (c) together with the receiver module (b) was placed on a second, repositionable platform (g), which could be moved, so that the distances between the transducers were set to 1, 2 or $3 \mathrm{~m}$ (threshold a). On the platform (g) there was also a calibrated and certified temperature measuring device (f)-Kestrel 4500NV [34]. The measurement results were sent from the receiving module (b) to a portable computer (i) and recorded. Inside the tunnel (d) there was also a gas heater (j) and an electric heater with a fan (k) mixing the air in the tunnel. By adjusting the heating intensity, the temperature inside the tunnel was controlled. The photo of the test stand is shown in Figure 11. 


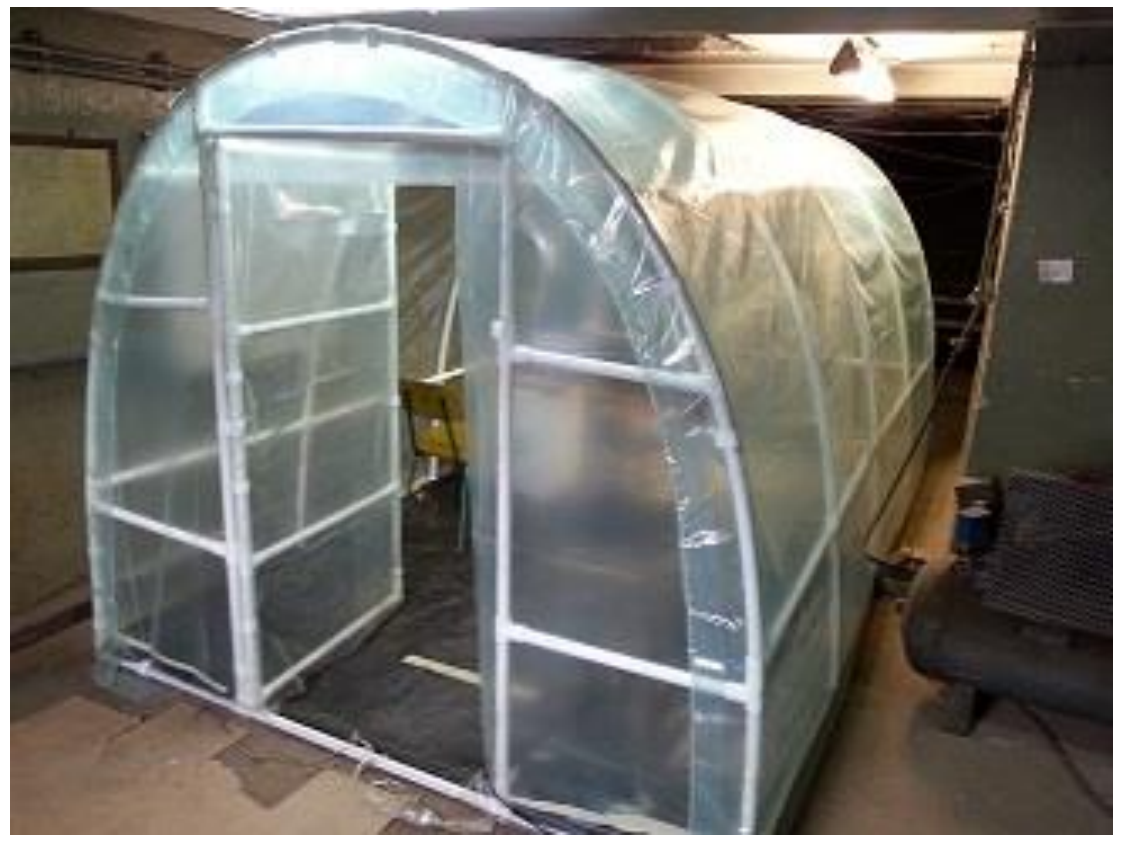

Figure 11. Photo of the tunnel enabling the simulation of various environmental conditions (temperature, and in the further part of the research-humidity).

Figure 12 shows the measured values of the ultrasonic wave propagation time as a function of temperature. The range of temperature changes was similar to the values that may occur in the real conditions of hard coal mine roadways. Measurements were made at three different distances between the transmitter and receiver: 1,2 and $3 \mathrm{~m}$. AR30 ultrasonic transducers were used in the experiment. Relative air humidity during the measurements was $50 \%$.

The obtained propagation time was converted into the propagation velocity of the ultrasonic wave, according to the following Equation (7):

$$
v_{U S}=\frac{d}{t_{p}}\left[\frac{\mathrm{m}}{\mathrm{s}}\right]
$$

where: $v_{U S}$ - ultrasonic wave propagation speed, $d$-the distance between transmitter and receiver, $t_{p}$-wave propagation time.

The graph of wave propagation velocity as a function of air temperature is shown in Figure 13. The velocities were averaged on the basis of three cases presented in Figure 12.

By approximating the results (Figure 13) to the form of a linear function, the equation of the ultrasonic wave propagation velocity as a function of temperature (8) was determined, which can be used to compensate for the influence of temperature changes on the values of the propagation time of ultrasonic waves, which will be developed as part of further work on the devices to accurately determine the location by measuring distances in the conditions of a hard coal mine.

$$
v_{U S}=0.628 \cdot T+332.02\left[\frac{\mathrm{m}}{\mathrm{s}}\right]
$$

where: $v_{U S}$-ultrasonic wave propagation speed, $T$-temperature $\left[{ }^{\circ} \mathrm{C}\right]$. 

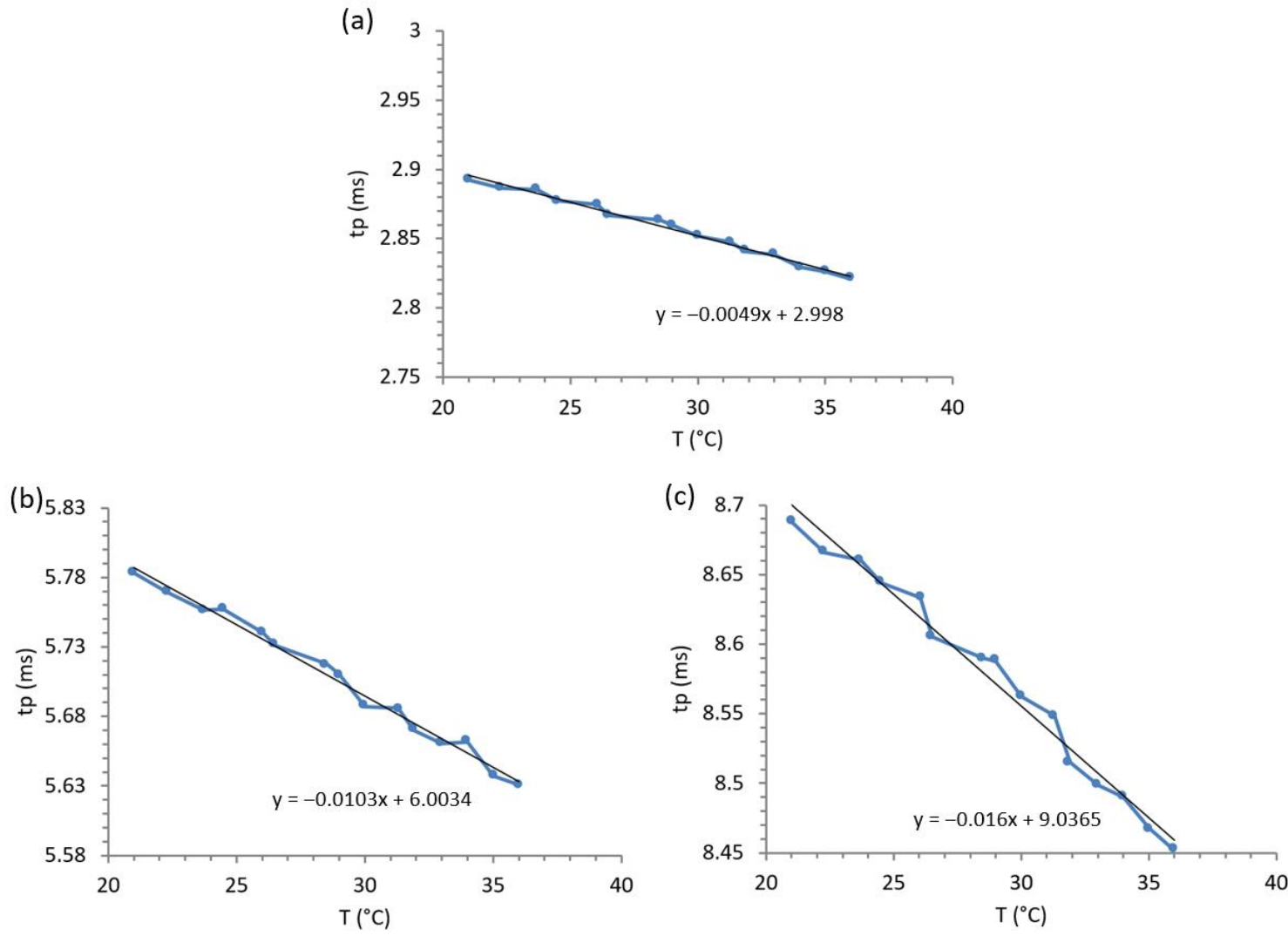

Figure 12. Graphs of propagation time depending on air temperature, along with the trend line and its equation at the following distances: (a) $1 \mathrm{~m}$, (b) $2 \mathrm{~m}$, (c) $3 \mathrm{~m}$.

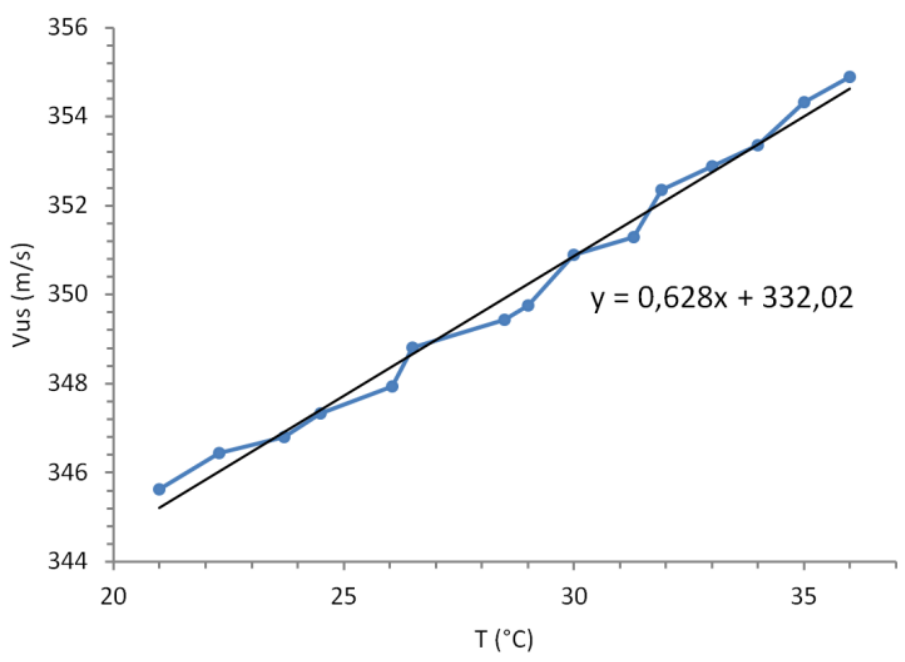

Figure 13. Dependence of average ultrasonic wave velocity on air temperature.

\section{Testing the Impact of Humidity Changes on the Propagation Time of Ultrasonic Waves}

Currently, most roadheaders are equipped with water or air-water spraying systems $[35,36]$. This is to generate water aerosol curtains that reduce dust concentration. Water aerosol can change humidity in the face of the developed roadway [37,38]. For this purpose, the impact of air humidity on the speed of ultrasonic wave propagation was tested. The test stand presented earlier in Figures 10 and 11 was used for the tests, where general purpose ultrasonic air humidifiers were added to increase and control air humidity. Figure 14 shows the diagrams of the propagation time of ultrasonic waves at distances of 1 , 2 and $3 \mathrm{~m}$. The temperature during the tests was $24^{\circ} \mathrm{C}$. 

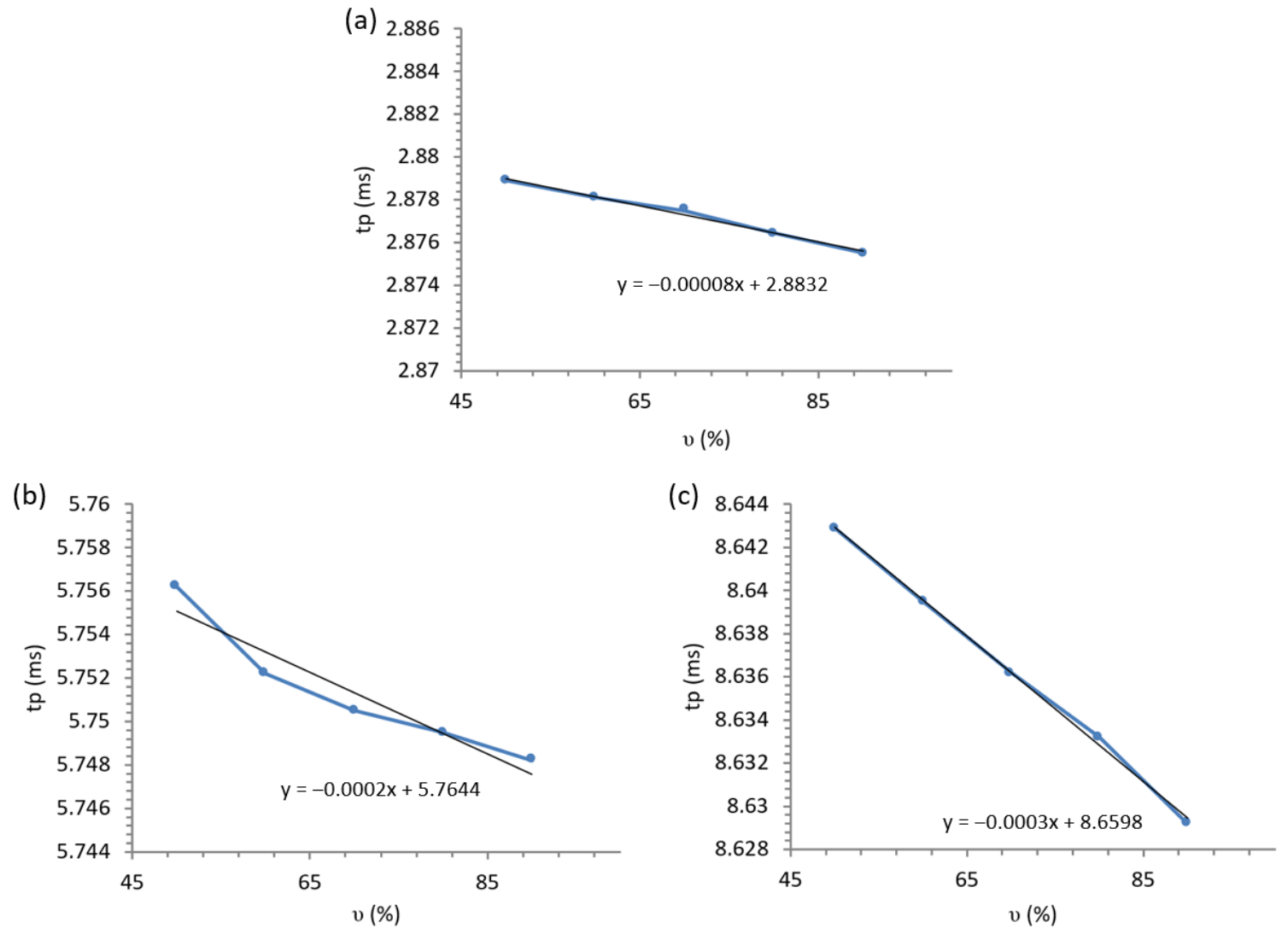

Figure 14. Graph showing the dependence of wave propagation time on air relative humidity at a distance of: (a) $1 \mathrm{~m}$, (b) $2 \mathrm{~m}$, (c) $3 \mathrm{~m}$.

The times obtained were converted into the speed of wave propagation. The averaged speed values from the three cases from Figure 14 are shown in Figure 15.

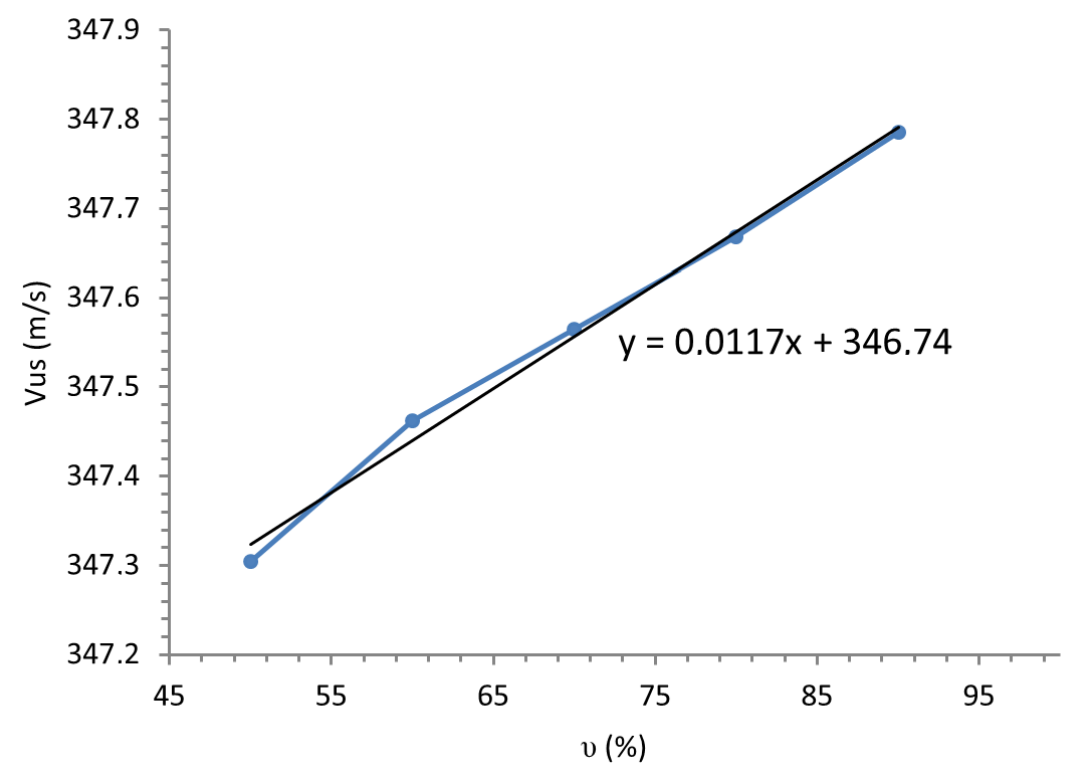

Figure 15. Dependence of the averaged ultrasonic wave propagation velocity as a function of air relative humidity.

The slope of the trend line obtained as a result of the approximation of the curve from Figure 15 indicates to what extent the wave propagation speed depends on the relative air humidity. The change in humidity in the range of $0-100 \%$ causes the change of the wave 
propagation speed by $0.37 \%$. The influence of relative humidity on the propagation speed of the ultrasonic wave is therefore much smaller than the influence of temperature. This indicates the possibility of omitting it at the stage of designing devices for accurate distance measurement, and then localization, in the conditions of a hard coal mine.

\section{Conclusions}

The tests of ultrasonic transducers in this and previous research projects allow concluding that it is possible and justified to use the ultrasonic technology for precise measurements of distances up to $30 \mathrm{~m}$ in a hard coal mine. This is an acceptable solution due to safety regulations in the conditions of mining in hard coal mines, in a situation, where other solutions are not recommended to be used, offer too low accuracy or are not convenient to use, e.g., due to the need for a problematic setup before starting the measurements, not resistant to significant dust concentration, humidity or temperature changes.

In the previous part of testing, the AR30 and AR41 ultrasonic transducers were pre-selected, the remaining components of the measurement system were selected and preliminary measurements of the propagation of ultrasonic waves without disturbances were carried out, taking into account the change in speed and direction of air movement in relation to the direction of ultrasound propagation. The results of these studies indicated the validity of the further project, allowing to determine the impact of other types and intensity of disturbances.

The tests on the impact of dust, air movement, humidity and temperature changes on the propagation speed of ultrasonic waves were possible due to the development of special equipment that allows simulating these phenomena in a controlled and repeatable manner. Two test stands were developed. The first of them allows the measurement of ultrasound propagation parameters in varying dust and air movement conditions, taking into account different directions of ultrasonic waves propagation in relation to the direction of air movement, as well as different concentrations and types of dust. The second enables measurements of ultrasound propagation at various temperatures and relative humidity.

The results of measurements of ultrasound propagation parameters in dust and air movement conditions using the first test stand indicate sufficient accuracy of measurements in typical conditions in hard coal mines, however, appropriate correction algorithms should be applied. The recorded values of the propagation time of ultrasonic waves were similar for all types of dust and the same sense of the propagation vector. This applies to the case of dusted air with a dust feeder capacity of $50 \%$ and $100 \%$, as well as non-dusted air, with an average flow velocity of $1 \mathrm{~m} / \mathrm{s}$. The type of dust used did not have a significant impact on the wave propagation time values, they were at a similar level.

However, a significant difference is caused by the change of the direction of the ultrasonic wave propagation vector in relation to the airflow vector, which is caused by the summation or mutual compensation of the velocity of these phenomena. The direction of the ultrasonic wave propagation vector consistent with the direction of the airflow vector reduces the measured time, while the opposite direction increases these values. Reference values described as "background" were recorded without introducing the dust and forced air movement. On the basis of a more detailed analysis, it can be concluded that the measurements with air movement are characterized by a much larger dispersion of values (measurement uncertainty) compared to the "background" measurements without forced air movement.

The maximum relative error of the measurements was about $1 \%$, regardless of the type of dust and its concentration, also the standard deviation did not depend on these parameters, which allows concluding that the measurement uncertainty does not depend on the type of dust and its concentration but depends on the airflow velocity and its homogeneity, as indicated by the theoretical analysis. Taking into account the average values and the averaged relative error, it is possible to show a slight increase in their values in the case of a dusty propagation medium, but the differences are small enough to be neglected. On this basis, it can be concluded that the concentration of dust in the atmosphere 
of hard coal mine roadways will not have a significant impact on the measurements of the propagation time of ultrasonic waves.

The results of measurements of ultrasound propagation at various temperatures (in the range of the expected changes in the conditions of a hard coal mine) indicate that the temperature has a noticeable effect on them, however, it is possible to correct this influence, and the value of the correction coefficient was determined as a result of the statistical analysis of the test results.

The results of measurements of ultrasound propagation time at a different relative humidity of the propagation environment, expected in a hard coal mine, indicate that the change in humidity has a minimal effect on the propagation times of ultrasonic waves. It is possible to correct this impact (the value of the correction factor was determined as a result of the statistical analysis of the research results), but it does not seem necessary.

It can therefore be concluded that the ultrasonic technology and AR30 and AR41 transducers selected for testing can be used for further research works aimed at the development of devices that allow for continuous or frequent determination of the position of the roadheader while drilling a roadway in a hard coal mine.

Author Contributions: Conceptualization, S.B. and G.K.; methodology, S.B. and G.K.; validation, G.K. and G.Ć.; formal analysis, S.B. and G.K.; investigation, S.B. and K.N.; resources, S.B. and K.N.; data curation, S.B., G.Ć. and G.K.; writing-original draft preparation, S.B., G.K., K.N. and G.Ć.; writing—review and editing, G.Ć. and S.B.; visualization, S.B. and G.Ć.; supervision, G.K. All authors have read and agreed to the published version of the manuscript.

Funding: This research work received no external funding.

Institutional Review Board Statement: Not applicable.

Informed Consent Statement: Not applicable.

Data Availability Statement: Not applicable.

Conflicts of Interest: The authors declare no conflict of interest.

\section{References}

1. Skołud, B.; Krenczyk, D.; Davidrajuh, R. Solving Repetitive Production Planning Problems. An Approach Based on Activityoriented Petri Nets. In Proceedings of the Advances in Intelligent Systems and Computing, Brno, Czech Republic, 20-22 June 2017; Volume 527, pp. 397-407.

2. Krenczyk, D.; Skolud, B.; Olender, M. Semi-automatic simulation model generation of virtual dynamic networks for production flow planning. IOP Conf. Ser. Mater. Sci. Eng. 2016, 145, 042021. [CrossRef]

3. Stańczak, L. Innovative techniques and technologies for the mining industry-conclusions from the KOMTECH-IMTech 2020 Conference. Min. Mach. 2020, 4, 67-74. [CrossRef]

4. Jasiulek, D.; Malec, M.; Polnik, B.; Stankiewicz, K.; Trenczek, S. State-of-the-art mechatronic systems for mining developed in Poland. In Mining Goes Digital; CRC Press: Boca Raton, FL, USA, 2019; pp. 686-694.

5. Stankiewicz, K. Mechatronic systems developed at the ITG KOMAG. Min. Mach. 2020, 2, 58-68. [CrossRef]

6. Deak, G.; Curran, K.; Condell, J. A survey of active and passive indoor localisation systems. Comput. Commun. 2012, 35, 1939-1954. [CrossRef]

7. $\quad$ Pirzada, N.; Nayan, M.Y.; Subhan, F.; Hassan, M.F.; Khan, M.A. Comparative Analysis of Active and Passive Indoor Localization Systems. AASRI Procedia 2013, 5, 92-97. [CrossRef]

8. Şahinoğlu, Z.; Gezici, S.; Güvenç, I. Ultra-Wideband Positioning Systems: Theoretical Limits, Ranging Algorithms, and Protocols; Cambridge University Press: Cambridge, UK; New York, NY, USA, 2008.

9. Laaraiedh, M.; Yu, L.; Avrillon, S.; Uguen, B. Comparison of Hybrid Localization Schemes Using RSSI, TOA, and TDOA. In Proceedings of the 17th European Wireless 2011-Sustainable Wireless Technologies, Vienna, Austria, 27-29 April 2011; pp. 626-630.

10. Bartoszek, S.; Stankiewicz, K.; Kost, G.; Ćwikła, G.; Dyczko, A. Research on Ultrasonic Transducers to Accurately Determine Distances in a Coal Mine Conditions. Energies 2021, 14, 2532. [CrossRef]

11. Kissel, F.N. Handbook for Dust Control in Mining; U.S. Department of Health and Human Services: Washington, DC, USA, 2003.

12. Belle, B.; Zyl, F.; Du Plessis, J.J. Summary Report on Underground Road Header Environmental Control; ESH 00-0206; CSIR Miningtek IMCL: Pretoria, South Africa, January 2002. 
13. Rozporządzenie Ministra Gospodarki z Dnia 28 Czerwca 2002 r. w Sprawie Bezpieczeństwa i Higieny Pracy, Prowadzenia Ruchu Oraz Specjalistycznego Zabezpieczenia Przeciwpożarowego w Podziemnych Zakładach Górniczych. (Dz.U.02.139.1169) (In Polish: Regulation of the Minister of Economy, 28 June 2002, on Occupational Health and Safety, Traffic Management and Specialist Fire Protection in Underground Mining Plants). 2002. Available online: https://isap.sejm.gov.pl/isap.nsf/DocDetails. xsp?id=WDU20021391169 (accessed on 21 September 2021).

14. Clarke-Hackston, N.; Belz, J.; Henneker, A. Guidance for Partial Face Excavation Machines. In Proceedings of the 1st International Conference on Machine Control \& Guidance, Zurich, Switzerland, 24-26 June 2008; pp. 1-6.

15. Sobczyk, E.J. Identyfikacja Parametrów Wpływających Na Efektywność Drążenia Wyrobisk Korytarzowych w Kopalniach Węgla Kamiennego (in Polish: Identification of parameters influencing the efficiency of drilling roadways in hard coal mines). Gór. Geoinżynieria 2010, 34, 199-214.

16. Bałaga, D.; Kalita, M.; Dobrzaniecki, P.; Jendrysik, S.; Kaczmarczyk, K.; Kotwica, K.; Jonczy, I. Analysis and Forecasting of PM2.5, PM4, and PM10 Dust Concentrations, Based on In Situ Tests in Hard Coal Mines. Energies 2021, 14, 5527. [CrossRef]

17. Prostański, D. Development of research work in the air-water spraying area for reduction of methane and coal dust explosion hazard as well as for dust control in the Polish mining industry. IOP Conf. Ser. Mater. Sci. Eng. 2018, 427, 012026. [CrossRef]

18. ATEX Directive 2014/34/EU. Available online: Eur-lex.europa.eu/legal-content/EN/TXT/?uri=celex\%3A32014L0034 (accessed on 4 September 2016).

19. Gudra, T. Właściwości i Zastosowanie Przetworników Ultradźwiękowych do Pracy w Ośrodkach Gazowych (in Polish: Properties and Application of Ultrasonic Transducers Operating in Gaseous Media); Oficyna Wydawnicza Politechniki Wrocławskiej: Wrocław, Poland, 2005.

20. Manthey, W.; Kroemer, N.; Magori, V. Ultrasonic transducers and transducer arrays for applications in air. Meas. Sci. Technol. 1992, 3, 249-261. [CrossRef]

21. Sharapov, V.; Sotula, Z.; Kunickaya, L. Piezo-Electric Electro-Acoustic Transducers; Springer: Singapore, 2014.

22. Borenstein, J.; Everett, H.R.; Feng, L. Where Am I-Systems and Methods for Mobile Robot Positioning; The University of Michigan: Ann Arbor, MI, USA, 1996.

23. Mautz, R. Indoor Positioning Technologies. 1 Band, 2012. Available online: https://doi.org/10.3929/ETHZ-A-007313554 (accessed on 23 September 2021). [CrossRef]

24. Kołakowski, J. Radiowe Techniki Lokalizacji Obiektów w Pomieszczeniach (in Polish: Radio techniques for locating objects indoors). Przeglad Telekomun. Wiad. Telekomun. 2011, 6, 206-213.

25. Schmitz, J.; Mathar, R.; Dorsch, D. Compressed time difference of arrival based emitter localization. In $20153 r d$ International Workshop on Compressed Sensing Theory and Its Applications to Radar, Sonar and Remote Sensing (CoSeRa); IEEE: Piscataway, NJ, USA, 2015; pp. 263-267.

26. Sanchez, A.; de Castro, A.; Elvira, S.; de Rivera, G.G.; Garrido, J. Autonomous indoor ultrasonic positioning system based on a low-cost conditioning circuit. Measurement 2012, 45, 276-283. [CrossRef]

27. Airmar Technology Corporation, Air Transducers. Available online: www.airmartechnology.com (accessed on 23 November 2019).

28. Jiang, W.; Xu, X.; Wen, Z.; Wei, L. Applying the similarity theory to model dust dispersion during coal-mine tunneling. Process. Saf. Environ. Prot. 2021, 148, 415-427. [CrossRef]

29. Yueze, L.; Akhtar, S.; Sasmito, A.P.; Kurnia, J.C. Prediction of air flow, methane, and coal dust dispersion in a room and pillar mining face. Int. J. Min. Sci. Technol. 2017, 27, 657-662. [CrossRef]

30. Lebecki, K. Zagrożenia Pyłowe w Górnictwie (in Polish: Dust-Related Hazards in Mining); Główny Instytut Górnictwa: Katowice, Poland, 2004.

31. Tecora. Individual Dust Sampler CIP10. Available online: www.tecora.com/en/produit/individual-dust-sampler-cip10 (accessed on 23 September 2021).

32. Szlązak, N.; Obracaj, D.; Szlązak, Ł. Zagrożenie pyłami szkodliwymi dla zdrowia w podziemnych wyrobiskach drążonych kombajnami chodnikowymi (in Polish: The risks caused by dust harmful to health in underground workings drilled with roadheaders). Gór. Geoinżynieria 2005, 3, 447-458.

33. Toraño, J.; Torno, S.; Menéndez, M.; Gent, M. Auxiliary ventilation in mining roadways driven with roadheaders: Validated CFD modelling of dust behaviour. Tunn. Undergr. Space Technol. 2011, 26, 201-210. [CrossRef]

34. KestrelMeters. Kestrel 4500 NV Applied Ballistics. Available online: Kestrelmeters.com/products/kestrel-4500nv-appliedballistics-meter?_pos=1\&_sid=4819d0ebb\&_ss=r (accessed on 20 January 2020).

35. Broen, A. Kombajny Chodnikowe (In Polish: Mining Roadheaders); Śląskie Wydawnictwo Techniczne: Katowice, Poland, 1993.

36. Bałaga, D.; Kalita, M.; Siegmund, M. Analysis of fraction distribution of the water drops stream generated by the spraying nozzles of new KOMAG design. IOP Conf. Ser. Mater. Sci. Eng. 2019, 545, 012010. [CrossRef]

37. Zhou, Q.; Qin, B. Coal dust suppression based on water mediums: A review of technologies and influencing factors. Fuel 2021, 302, 121196. [CrossRef]

38. Bałaga, D.; Siegmund, M.; Kalita, M.; Williamson, B.J.; Walentek, A.; Małachowski, M. Selection of operational parameters for a smart spraying system to control airborne PM10 and PM2.5 dusts in underground coal mines. Process. Saf. Environ. Prot. 2021, 148, 482-494. [CrossRef] 